\title{
Social Capital and Health-related Quality of Life of Older Adults Living in Thai Rural Areas
}

\author{
Kana Nishino $^{1}$, Sayaka Kotera ${ }^{2, *}$, Arbkhanok Tongtham ${ }^{3}$ \\ ${ }^{1}$ Infectious Disease Countermeasures Division, Ota City, Tokyo, Japan \\ ${ }^{2}$ Graduate School of Health Sciences, Kobe University, Japan \\ ${ }^{3}$ Department of Community Health Nursing, Srisavarindhira Thai Red Cross Institute of Nursing, Thailand
}

Received June 16, 2021; Revised August 24, 2021; Accepted September 21, 2021

\section{Cite This Paper in the following Citation Styles}

(a): [1] Kana Nishino, Sayaka Kotera, Arbkhanok Tongtham, "Social Capital and Health-related Quality of Life of Older Adults Living in Thai Rural Areas," Universal Journal of Public Health, Vol. 9, No. 5, pp. 306 - 316, 2021. DOI: 10.13189/ujph.2021.090513.

(b): Kana Nishino, Sayaka Kotera, Arbkhanok Tongtham (2021). Social Capital and Health-related Quality of Life of Older Adults Living in Thai Rural Areas. Universal Journal of Public Health, 9(5), 306 - 316. DOI: 10.13189/ujph.2021.090513.

Copyright $(2021$ by authors, all rights reserved. Authors agree that this article remains permanently open access under the terms of the Creative Commons Attribution License 4.0 International License

\begin{abstract}
Thailand is one of the most aging countries in Southeast Asia. While family support for Thai older adults is dominant, mutual support in communities is needed in response to the demographic shifts. The purpose of this study was to explore the impact of individual social capital on health-related quality of life (QOL) as a health outcome of older adults living in rural Thai communities. The questionnaire comprised the following: general characteristics, the Shortened and Adapted Social Capital Assessment Tool (SASCAT) and other items of social capital, the 12-Item Short-Form Health Survey (SF-12), and life satisfaction. We collected data from 202 older adults who participated in elderly clubs. After controlling for confounding effects, logistic regression analysis revealed that less group membership and more support from individuals were significantly associated with better physical QOL. Feeling safe in the community was significantly associated with mental QOL. However, other components of SASCAT, such as citizenship activities and cognitive social capital, had no significant associations. This study suggests that health-related QOL of Thai older adults may be improved by increasing mutual support of community members and perceived neighborhood safety through feeling supported by a community. However, it should be noted that multiple active memberships may adversely affect the health of older adults in Thailand.
\end{abstract}

Keywords Social Capital, Health-related Quality of Life, Older Adults, Rural Community, Thailand

\section{Introduction}

Virtually, every country whether it is a high-, middle-, or a low-income country, is experiencing an increase in the size and proportion of persons aged 65 years and above. In Southeast Asia, Thailand and Singapore have the highest percentage of older adults in their populations [1]. In addition to the rising number of older adults, the rapid pace of aging is even more concerning. In 2005, Thailand became an aging society in that its proportion of older adults exceeded $7 \%$ of its population. Furthermore, per another criterion that describes the proportion of older adults as over $14 \%$, Thailand will become even more of an aged society in 2021 and a super-aged society by 2050 , according to the United Nations [2]. This means that the time to prepare for subsequent demographic changes is short in Thailand. Due to the country's economic and social improvements, life expectancy at birth has drastically increased over the past 3 decades [3]. However, the "unhealthy" period, calculated from the differences between life expectancy and healthy life expectancy (HALE), has also extended [3]. Moreover, the National Statistical Office of Thailand has reported that one-third of older people experience chronic health conditions, such as diabetes, hypertension, and cardiovascular and cerebrovascular diseases [4]. Accordingly, the Thai 
government has strongly focused on developing care services for older people [5]. Therefore, effective strategies to improve HALE are needed to promote active aging in Thailand.

Social factors are known to be social determinants of health. Social capital plays a crucial role in individual health, use of healthcare services, and health behaviors among the social factors [6]. However, since social capital has its roots in multi-disciplinary fields such as sociology, political science, economics, and business administration, there has been a lack of consensus of its definition and various measurements of social capital $[7,8]$. In terms of its impact on health, there are two positions regarding the concept of social capital. One is to think of it as a group or community characteristic represented by social cohesiveness. The other is considering it an individual characteristic represented by a network $[8,9]$. Kawachi and Berkman [10], who first pointed out the significance of social capital and have led research on social capital in the field of public health, define social capital as "resources that are accessed by individuals as a result of their membership of a network and a group." This implies that social capital includes both individual and group or community levels.

Many studies have investigated the association between social capital and health-related variables in various groups and populations. Most of them have found that social capital is an important determinant of physical and mental health [11-14]. Empirical gerontological studies focusing on older adults have identified that social capital is associated with better physical and mental health, self-rated health, and life satisfaction, and lower mortality rate of older adults [15-19].

However, most studies have explored the impact of social capital on the health of older adults in high-income countries. Limited studies have focused on middle-income countries experiencing the rapid growth of the aging population, particularly in Southeast Asia.

Traditionally, family members, particularly children, are the main source of support, including economic and material support, for older adults in Thailand. This informal support system within families is crucial in maintaining the well-being of Thai older adults [20,21]. However, with the current demographic and social changes, family size is continuously reducing. The number of older adults living with children has declined steadily from $71 \%$ in 1994 to $52 \%$ in 2017 [21]. While family support is decreasing, social or community support has been increasingly emphasized to promote active aging in Thai older adults. Participation in social activities and involvement in social networks, including Buddhist social networks, are positively associated with better functional and mental status and reported good health in Thai older adults [22-26]. However, empirical gerontological studies of Thai social capital and health have not been fully accumulated. Making the best of the social capital of elderly Thai individuals to promote their health must be discussed.

Therefore, this study aimed to explore the impact of individual social capital on the health-related quality of life (QOL) of older adults in Thai communities. This country is the most rapidly aging in Southeast Asia. It is important to clarify how the social capital of the elderly population is associated with their health and QOL in this region. Valuable suggestions must be obtained for measures that can effectively promote the health of older adults by utilizing social capital in rural locations or in other rapidly aging developing countries where human and social resources are more limited.

\section{Materials and Methods}

\subsection{Participants}

This study targeted older adults living in the Mueang Chiang Mai District of Chiang Mai Province in Northern Thailand. Mueang Chiang Mai is the capital district in that province. Convenience sampling was used to identify and recruit six elderly clubs as the sample. They were also selected based on the advice and information from one of the community health centers covering Chiang Mai District. An elderly club has been established by the local government in Thailand to promote social activities, such as exercise and recreations for older adults at the sub-district level. All local elderlies (60 years and older) are invited to become members free of charge, regardless of social status differences. It was reported that about a third participated in the club [27]. In this study, the inclusion criteria were those aged 60 years and above and voluntary participation. The exclusion criteria were those who were bedridden and severe cognitive impairment.

\subsection{Data Collection}

A questionnaire survey was conducted in March 2015. We explained the objectives of this study, its methodology, and the ethical considerations to all the participants who attended the activities of the senior clubs by chance. We distributed a self-administered questionnaire to those who consented to participate in this study. The answers were collected simultaneously. The nurses who worked in the health center were recruited and trained via lectures to ensure the quality and consistency of the data collection.

We obtained ethical approval from the Institutional Review Board of Kobe University Graduate School of Health Sciences (no. 430). A written or verbal explanation of the ethical considerations was provided for each participant. The explanation included the voluntary cooperation, protection of personal information, and confidentiality. 


\subsection{Instruments}

The questionnaire comprised social capital components, health-related QOL, and general characteristics, and it was translated from English to Thai.

The short version of the Adapted Social Capital Assessment Tool (SASCAT), which was developed by Harpham et al. [28], was used to assess individual social capital. The SASCAT has sub-concepts of structural social capital and cognitive social capital. Structural social capital, including social networks and social support, can be objectively verified. Cognitive social capital includes subjective values and perceptions, such as interpersonal trust and sense of belonging. The SASCAT has been used in studies in low- and middle-income Asian countries, including Vietnam and the Lao People's Democratic Republic $[29,30]$. Construct validity has been revealed in previous studies [28]. Because culture can influence social capital, we changed some items to reflect the Thai context based on the ideas of Thai community nursing specialists. The original SASCAT was back-translated into the Thai version (Table 1) after obtaining permission from the developer. In addition, two questions on social capital were included: "Do you feel safe walking down your street after dark?" and "Do you feel valued by society?" These were extracted from the other social capital scale developed by Onyx et al. [31].

Table 1. Short version of the Adapted Social Capital Assessment Tool

\begin{tabular}{|c|c|}
\hline $\begin{array}{l}\text { Group membership } \\
\text { Q1. In the last } 12 \text { months have you been an active member of any of the following types of groups } \\
\text { in your community? } \\
\diamond \text { Work related/trade union } \\
\diamond \text { Credit/funeral group } \\
\diamond \text { Community association/coop } \\
\diamond \text { Sport group } \\
\diamond \text { Women's group } \diamond \text { Volunteer group } \\
\diamond \text { Religious group } \\
\diamond \text { Art \& culture conservation } \\
\diamond \text { Political group } \diamond \text { Other specify }\end{array}$ & $\begin{array}{c}1 \text { item }=1 \\
\text { (score range } 0-10 \text { ) }\end{array}$ \\
\hline $\begin{array}{l}\text { Support from groups } \\
\text { Q2. In the last } 12 \text { months, did you receive from the group any emotional help, economic help or } \\
\text { assistance in helping you know do things? } \\
\diamond \text { Work related/trade union } \\
\diamond \text { Credit/funeral group } \\
\diamond \text { Community association/coop } \\
\diamond \text { Sport group } \diamond \text { Women's group } \\
\diamond \text { Volunteer group } \diamond \text { Religious group } \\
\diamond \text { Art \& culture conservation } \\
\diamond \text { Political group } \diamond \text { Other specify }\end{array}$ & $\begin{array}{c}1 \text { item }=1 \\
\text { (score range } 0-10 \text { ) }\end{array}$ \\
\hline $\begin{array}{l}\text { Support from individuals } \\
\text { Q3. In the last } 12 \text { months, have you received any help or support from any of the following, this can } \\
\text { be emotional help, economic help or assistance in helping you know or do thing? } \\
\diamond \text { Family } \quad \diamond \text { Neighbors } \\
\diamond \text { Friends } \quad \diamond \text { Community leaders } \\
\diamond \text { Politician } \\
\diamond \text { Government officials/civil service } \\
\diamond \text { Charitable organization/NGO } \\
\diamond \text { Religious leader } \diamond \text { Other specify }\end{array}$ & $\begin{array}{c}1 \text { item }=1 \\
\text { (score range } 0-9 \text { ) }\end{array}$ \\
\hline $\begin{array}{l}\text { Citizenship activities } \\
\text { Q4. In the last } 12 \text { months, have you joined other community members to address a problem or } \\
\text { common issues? } \\
\text { Q5. In the last } 12 \text { months, have you talked with a local authority or governmental organization } \\
\text { about problems in this community? }\end{array}$ & $\begin{array}{c}\text { Yes }=1 \\
\text { No }=0 \\
\text { Yes }=1 \\
\text { No }=0\end{array}$ \\
\hline $\begin{array}{l}\text { Cognitive social capital } \\
\text { Q6. In general, can the majority of people in this community be trusted? } \\
\text { Q7. Do the majority of people in this community generally get along with each other? } \\
\text { Q8. Do you feel as though you are really a part of this community? } \\
\text { Q9. Do you think that the majority of people in this community would try to take advantage of you } \\
\text { if they got the chance? }\end{array}$ & $\begin{array}{l}\text { Yes }=1 \\
\text { No }=0 \\
\text { Yes }=1 \\
\text { No }=0 \\
\text { Yes }=1 \\
\text { No }=0 \\
\text { Yes }=0 \\
\text { No }=1\end{array}$ \\
\hline
\end{tabular}

NGO: non-governmental organization. 
We also used the Thai version of the 12-Item Short-Form Health Survey (SF-12) [32] to assess functional health and well-being. The SF-12 was culturally adapted and translated using the linguistic validation method developed by the MAPI Research Institute. It is a widely used tool for evaluating comprehensive health-related QOL and can be used for various populations, including healthy people and patients. It comprises two psychometric-based components: a physical component summary (PCS) score and a mental component summary (MCS) score.

The general characteristics included socio-economic factors, health status, and life satisfaction. The socio-economic factors included age, gender, marital status, family size and members, educational level, daily activity, income perception for themselves, religion, and years of residence. The health status in this study was measured as having an illness. Life satisfaction was measured using the Thai version of the Satisfaction with Life Scale (SWLS), originally developed by Diener et al. [33]. The SWLS was designed to measure global cognitive judgments of satisfaction with one's life. It comprises five items rated on a seven-point Likert scale ranging from 1 (strongly disagree) to 7 (strongly agree). A higher total score indicates higher life satisfaction. Good internal consistency was revealed with a Cronbach's alpha coefficient of .88 in our sample, which is close to .85 that was reported by developers of the scale [33].

\subsection{Data Analysis}

SPSS version $24.0 \mathrm{~J}$ was used for all statistical analyses. Descriptive analyses were employed to describe the central tendencies of all the variables. Chi-square tests were used to examine bivariate associations between all the variables and health-related QOL. Fisher's exact test was also used as the sample size was small, with $\leq 5$ in a cell. We also assessed the potential determinants of the social capital components for health-related QOL using logistic regression analysis. To use logistic regression, health-related QOL was divided into two groups according to the median: higher scoring (high) and lower scoring (poor). We also dichotomized social capital and the other variables to simplify the analysis and interpretation of the results. Logistic regression analysis (forward-backward stepwise selection method) was performed and adjusted by the demographic variables that showed significant differences in each bivariate analysis. Parallelly, the results were demonstrated as odds ratio (OR) and 95\% confidence intervals (CIs). The level of significance was set at $p<.05$.

\section{Results}

\subsection{General Characteristics}

Table 2 shows the characteristics of the 202 respondents according to their gender ( $76 \%$ female). The mean age was 70.8 years for males and 70.0 years for females. Most male respondents were married $(70.8 \%)$, while half of the female respondents were widowed $(52.6 \%)$. Over $90 \%$ of the respondents lived with their family, of which children were the most common family members among both genders. Most respondents (over 80\%) received a government pension. Of all respondents, $35.4 \%$ males and $46.8 \%$ females perceived that they had sufficient income for themselves, and $70.8 \%$ males and $81.8 \%$ females had only an elementary school education. Almost all respondents were Buddhist. The mean years of living in the community were 55.2 years for males and 54.0 for females. Regarding their health status, over $70 \%$ of the respondents were being treated for one or more illnesses $(72.9 \%$ males and $77.3 \%$ females), including hypertension and diabetes. The mean SWLS score was 29.6 for males and 31.2 for females. 
Table 2. General characteristics

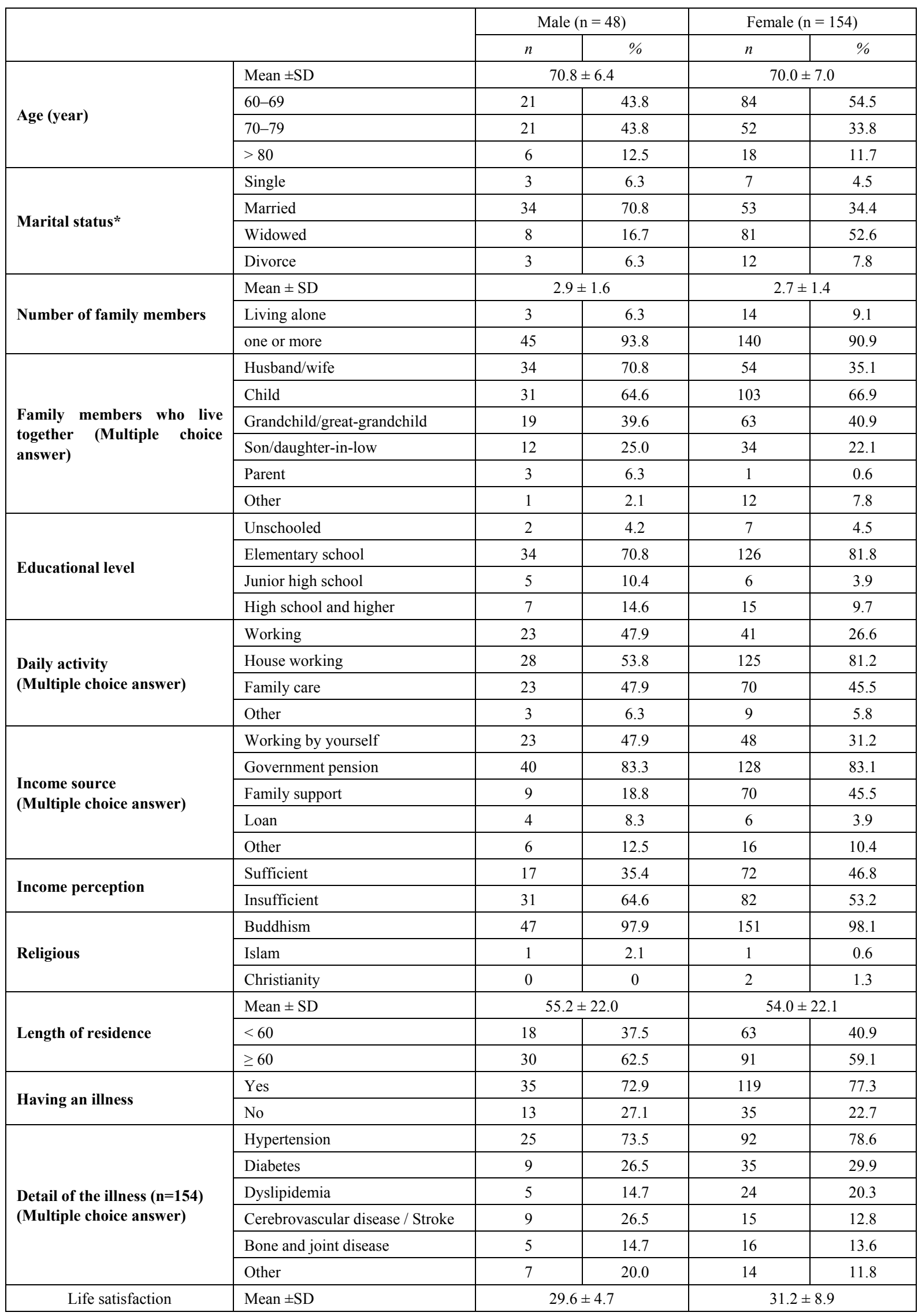

* Subjects with missing data were excluded from the analysis. SD: standard deviation. 


\subsection{Social Capital}

Regarding individual social capital, the average scores of group membership was 2.7 ( \pm 1.5$)$, with the credit/funeral group having the highest score at 136 (67.7\%), followed by the religious group at $115(57.2 \%)$. Similarly, the average score for support from groups was $2.4( \pm 1.6)$, with the religious and sport groups having the highest score at $112(55.4 \%)$, respectively, followed by the credit/funeral group at $84(41.6 \%)$. The average support score from individuals was $3.7( \pm 2.3)$, with family having the highest score at 147 (59.0\%), followed by charitable organization/NGO with $116(57.4 \%)$ and neighbors with $113(55.9 \%)$. The average scores of citizenship activities were $1.6( \pm 0.6)$. On questions related to cognitive social capital, 141 (70.5\%) participants scored 4 (of 4 ), with an average score of 3.6 $( \pm 0.7)$.

\subsection{Association between Health-related Quality of Life and the Social Capital Components and Other Variables}

In the binary analysis, we found significant associations between some variables and health-related QOL. As shown in Table 3, income perception ( $p=.046)$, having an illness $(p<.000)$, group membership $(p=.047)$, and cognitive social capital $(p=.003)$ were significantly associated with PCS. Those with a sufficient income, no illnesses, fewer group memberships, and higher cognitive social capital were more likely to have a higher PCS. Life satisfaction ( $p$ $=.009)$ and feeling safe $(p=.031)$ were significantly associated with MCS. Those with a higher life satisfaction and who felt safe in their community were more likely to have higher MCS.

Table 3. Association between health-related quality of life, the social capital components, and other variables



${ }^{*} \mathrm{p}<0.05,{ }^{* *} \mathrm{p}<0.01, * *{ }^{*} \mathrm{p}<0.001$. PCS: physical component summary; MCS: mental component summary; SC: social capital. 
Table 4. Bivariate logistic regression of the associations between the social capital components and the health-related quality of life

\begin{tabular}{|c|c|c|c|c|c|c|}
\hline & \multicolumn{3}{|c|}{$\mathrm{PCS}^{\mathrm{a}}$} & \multicolumn{3}{|c|}{$\mathrm{MCS}^{\mathrm{b}}$} \\
\hline & OR & $95 \% \mathrm{CI}$ & $P$ & OR & $95 \% \mathrm{CI}$ & $P$ \\
\hline \multicolumn{7}{|c|}{ Group Membership } \\
\hline$<1$ & 1 & \multirow{2}{*}{$0.137-0.970$} & \multirow{2}{*}{$0.043^{*}$} & 1 & \multirow{2}{*}{$0.313-1.834$} & \multirow{2}{*}{0.539} \\
\hline$\geq 2$ & 0.365 & & & 0.758 & & \\
\hline \multicolumn{7}{|c|}{ Support from Groups } \\
\hline$<1$ & 1 & \multirow{2}{*}{$0.567-3.336$} & \multirow{2}{*}{0.481} & 1 & \multirow{2}{*}{$0.289-1.530$} & \multirow{2}{*}{0.337} \\
\hline$\geq 2$ & 1.375 & & & 0.665 & & \\
\hline \multicolumn{7}{|c|}{ Support from Individuals } \\
\hline$<1$ & 1 & \multirow{2}{*}{$1.005-6.213$} & \multirow{2}{*}{$0.049^{*}$} & 1 & \multirow{2}{*}{$0.555-3.229$} & \multirow{2}{*}{0.516} \\
\hline$\geq 2$ & 2.499 & & & 1.339 & & \\
\hline \multicolumn{7}{|c|}{ Citizenship Activities } \\
\hline$<1$ & 1 & \multirow{2}{*}{$0.669-2.876$} & \multirow{2}{*}{0.379} & 1 & \multirow{2}{*}{$0.391-1.570$} & \multirow{2}{*}{0.491} \\
\hline 2 & 1.388 & & & 0.783 & & \\
\hline \multicolumn{7}{|l|}{ Cognitive SC } \\
\hline $0-3$ & 1 & \multirow{2}{*}{$0.901-4.343$} & \multirow{2}{*}{0.089} & 1 & \multirow{2}{*}{$0.393-1.808$} & \multirow{2}{*}{0.661} \\
\hline 4 & 1.978 & & & 0.843 & & \\
\hline \multicolumn{7}{|l|}{ Feel Safe } \\
\hline No & 1 & \multirow{2}{*}{$0.577-2.529$} & \multirow{2}{*}{0.617} & 1 & \multirow{2}{*}{$1.519-7.020$} & \multirow{2}{*}{$0.002^{*}$} \\
\hline Yes & 1.208 & & & 3.263 & & \\
\hline
\end{tabular}

${ }^{a}$ Adjusted by age, gender, education level, income perception, and having an illness. ${ }^{b}$ Adjusted by age, gender, education level, and life satisfaction. ${ }^{*} \mathrm{p}<0.05, * * \mathrm{p}<0.01$. PCS: physical component summary; MCS: mental component summary; OR: odds ratio; CI: confidence interval; SC: social capital.

Table 4 shows the logistic regression of the association between the social capital components and health-related QOL. This considers age, gender, education level, income perception, illness in PCS, and age, gender, education level and life satisfaction in MCS as the control variables, respectively. Individuals with fewer group memberships (odds ratio [OR]: 0.37, 95\% confidence interval [CI]: 0.140.97 ) and more support from other individuals (OR: 2.50, 95\% CI: 1.01-6.21) were more likely to have a higher PCS. Those who felt safe in their community (OR: $0.3 .26,95 \%$ CI: 1.52-7.02) were more likely to have a higher MCS.

\section{Discussion}

This study aimed to clarify the association between the health-related QOL and social capital of older adults living in rural areas in Thailand. The results revealed that women accounted for $76 \%$ of the participants, higher than $55 \%$ of the people aged 60 and older in a recent national survey because women are expected to be more involved in social activities than men. In addition, compared to the national survey, the study revealed a higher proportion of older adults living with children, which is a traditional Thai family structure, and a higher number of working older adults, which were congruent with the characteristics of rural elders [27].

\subsection{Association between Social Capital and Health-related Quality of Life}

In terms of social capital and health-related QOL, the logistic regression analysis showed that some social capital components were associated with health-related QOL. First, it should be noted that the higher the number of group memberships, which is one of the structural social capital items, the significantly lower the PCS was after adjusting for the individual-level sociodemographic variables. Regarding cognitive versus structural social capital, both are associated with different health outcomes [7]. It has been reported that a lack of social participation and social network, represented by group membership, has a positive effect on lowering older adults' risk of death [19], self-rated health, and geriatric depression $[4,5,22,23]$.

There are two possible reasons for the adverse effects on physical QOL found in this study. One reason is that social activities affect some health aspects, as indicated by the negative impact of social capital. According to Bourdieu's social capital theory, neighborhood social capital can produce negative and positive health consequences [34]. 
Particularly, neighborhood organization participation, such as participation in community associations, may cause health disadvantages. The demands of being involved in the neighborhood community expose the elderly to more health risks. In this study, having more group memberships might have restricted the elderly's time and activities. Thus, group membership was negatively associated with physical QOL.

The other reason is that people who have lower physical QOL, such as those in pain and distress, may seek to connect with other people to reduce the stress caused by the physical problems. These problems are said to be mediating factors in social capital. Another study of Thai older adults reported that those with lower economic status felt more anxious about the future. However, they actively participated in social activities, such as those in the community [4]. Emotional stress, such as physical and financial anxiety, is considered to promote participation in social activities. Since this was a cross-sectional study, the causal relationship is unknown. In the future, it will be necessary to investigate further the motivations and reasons for the social participation of people with low physical QOL. Moreover, group membership was measured as the number of groups they actively participated in rather than the quality of activities. However, health effects may vary depending on the groups or organizations to which they belong. Therefore, the quality of the relationship of each social activity should be carefully examined.

Receiving support from individuals is a component of structural social capital. Some studies have shown that social support is positively associated with mental health [35]. However, it was significantly associated with better physical QOL, and not mental QOL in this study after adjusting for covariates. Social support is well known as a beneficial factor in health, and it has a positive effect on many aspects of both physical and mental health. The influence of social support on health has been reported to act through direct and buffering mechanisms [36]. The direct effect on health may be through health behavioral pathways. Connections with and support from others may encourage healthier behaviors, such as exercising. As a buffering effect, psychological pathways are considered. Practical or emotional support may help mitigate the effects of latent stressors and perceived stress, which can improve health and health behaviors. These effects may be related to better physical health in this study. In contrast, poor physical health might limit connecting with others or engaging in social activities, especially in older adults. In other words, good physical health could lead to increased social support from others.

Cognitive social capital, which reflects residents' perceptions of community quality, is generally related to cognitive health, such as mental health and pain [37]. In this study, there was a significant positive relationship between feelings of safety in the community and MCS.
This finding is congruent with the previous evidence that perceived neighborhood safety is associated with a greater overall and mental well-being [38,39]. The actual and perceived neighborhood safety can be generated from informal social control. This control is one of the forms of social capital and affects health through monitoring and surveillance of the local communities [40]. Two possible mechanisms are linking perceived community safety and mental QOL. First, more cohesive neighborhoods have the potential to promote more social interactions and community involvement. Second, social cohesion may also facilitate psychological stress reduction for fear of crime [41] and older adults feeling supported by a community. These mechanisms could improve mental health among older adults.

On the other hand, none of the cognitive social capital components of the SASCAT were significant in the logistic regression analysis. The participants' average cognitive social capital score in this study was 3.6 (out of a possible range of 0-4), and the median score was of a high value of 4. In addition, almost all the participants answered "yes" to the question "Do you feel valued by society?" It is suggested that many of the participants in this study had relatively high cognitive social capital, which might have no association with MCS. Thailand is one of the world countries with high social capital based on the traditional Thai community, ranking twenty-third out of 167 countries [42]. This community is rooted in Buddhist social networks and financial support networks in rural communities $[26,43]$. This may have affected the results of this study.

The results have shown the importance of individual social capital for improving the health of older adults living in Thai rural areas. Many participants in this study lived with their families and received support from them. However, physical QOL was higher among those who received support from multiple individuals, including those other than their families. Although family safety nets are still crucial for older adults in Thai rural areas, this study indicates that support from others, such as neighbors, is also essential in promoting health. Intervention programs such as health promotion activities to foster reciprocal relationships within a community would benefit Thai older adults. The existing social capital in the traditional Thai community can promote the development of a program effectively. For older adults with low individual social capital and who cannot reach any support, the involvement of social policy to develop new voluntary support groups and organizations within the community would be necessary.

\subsection{Limitations of the Study}

First, the participants in this study were individuals who took part in senior clubs, seemed to be socially active, and had higher health awareness in specific areas and cultures. 
This limits the generalizability of the findings to apply other elderly populations, such as those who belong to no groups or live in areas with different socio-cultural backgrounds. Second, a consistent definition of social capital has not been established, and indicators of studies to assess social capital vary. Thus, the results of this study may be limited to the use of SASCAT. In addition, since this is a cross-sectional study with a small sample size, further prospective and large-scale research is needed to clarify the impact of social capital on the health of Thai older adults.

\section{Conclusions}

This study examined the association between social capital and the health-related QOL of older adults living in rural Thailand. The results indicated that those with less social participation and more support from individuals had better physical well-being. We also found that individuals who thought that the community was safe had better mental well-being. The study results suggest that health-related QOL may be improved by increasing mutual support as a form of structural social capital and neighborhood safety as a form of cognitive social capital.

\section{Acknowledgements}

The authors gratefully acknowledge the nurses of Red Cross Health Station Number 3 and all of the participants who were members of the senior clubs in the Mueang Chiang Mai District.

\section{Conflicts of Interest}

The authors declare no competing interests.

\section{REFERENCES}

[1] United Nations, "World Population Ageing 2019," United Nations, https://www.un.org/en/development/desa/populati on/publications/pdf/ageing/WorldPopulationAgeing2019Report.pdf (accessed Apr, 21, 2021)

[2] United Nations, "World Population Prospects 2019," United Nations, https://population.un.org/wpp/Publications/Files/ WPP2019 Volume-II-Demographic-Profiles.pdf (accessed Apr, 21, 20ㄹ)

[3] World Health Organization, "The Global Health Observatory," World Health Organization, https://www.wh o.int/data/gho/data/themes/topics/indicator-groups/indicato r-group-details/GHO/life-expectancy-and-healthy-life-expe ctancy (accessed Mar, 24, 2021)

[4] Somrongthong R., Wongchalee S., Ramakrishnan C.,
Hongthong D., Yodmai K., N. Wongtongkam, "Influence of Socioeconomic Factors on Daily Life Activities and Quality of Life of Thai Elderly," Journal of Public Health Research, vol. 6, no. 1, p. 862, 2017. DOI: 10.4081/jphr.2017.862.

[5] Makabe S., Kume Y., Kamata T., Apikomonkon H., Griffiths J., Takagai J., Akagawa Y., Andoh H., Ito T., N. Singha-Dong, "Health Promotion Awareness in Barbershops and Salons: An International Cross-Sectional Survey in Japan and Thailand," Journal of Community Health, vol. 45, no. 4, pp. 768-774, 2020. DOI: 10.1007/s10900-020-00792-1.

[6] Peng Y., T.F. Lin, "Social capital and preventive care use among the elderly under Taiwan's National Health Insurance," Archives of Gerontology and Geriatrics, vol. 75, pp. 28-36, 2018. DOI: 10.1016/j.archger.2017.11.002

[7] Kawachi I., Subramanian S.V., D. Kim, "Social Capital and Health: A Decade of Progress and Beyond," in Social Capital and Health, Springer, 2008, pp. 1-26.

[8] M. Paldam, "Social Capital: One or Many? Definition and Measurement," Journal of Economic Surveys, vol. 14, no. 5, pp. 629-653, 2000. DOI: 10.1111/1467-6419.00127.

[9] Aida J., K. Kondo, "Social Capital and Health Inequalities," Journal of Health Care and Society, vol. 24, no. 1, pp. 5774, 2014. (in Japanese) DOI: 10.4091/iken.24.57

[10] Kawachi I., L. F. Berkman, "Social capital, social cohesion, and health," in Social Epidemiology, 2nd ed, Oxford University Press, 2014, pp. 290-319.

[11] Novak D., Suzuki E., I. Kawachi, "Are family, neighbourhood and school social capital associated with higher self-rated health among Croatian high school students? A population-based study," BMJ Open, vol. 5, no. 6, p. e007184, 2015. DOI: 10.1136/bmjopen-2014-007184.

[12] Flores E.C., Carnero A.M., A.M. Bayer, "Social capital and chronic post-traumatic stress disorder among survivors of the 2007 earthquake in Pisco, Peru," Social Science and Medicine, vol. 101, pp. 9-17, 2013. DOI: 10.1016/j.socsci med.2013.11.012.

[13] Fujino Y., Kubo T., Kunimoto M., Tabata H., Tsuchiya T. Kadowaki K., Nakamura T., I. Oyama, "A cross-sectional study of workplace social capital and blood pressure: a multilevel analysis at Japanese manufacturing companies," BMJ Open, vol. 3, no. 2, p. e002215, 2013. DOI: 10.1136/bmjopen-2012-002215.

[14] Choi M., Frias M.M., Nuesch E., Hargreaves J., Prieto-Merino D., Bowling A., Snith G.D., Ebrahim S., Dale C., J.P. Casas, "Social capital, mortality, cardiovascular events and cancer: a systematic review of prospective studies," International Journal of Epidemiology, vol. 43, no. 6, pp. 1895-1920, 2014. DOI: $10.1093 / \mathrm{ije} / \mathrm{dyu} 212$.

[15] Han K.M., Han C., Shin C., Jee H.J., An H., Yoon H.K., Ko Y.H., S.H. Kim, "Social capital, socioeconomic status, and depression in community-living elderly," Journal of Psychiatric Research, vol. 98, pp. 133-140, 2018. DOI: 10.1016/j.jpsychires.2018.01.002.

[16] Kim E.K., Jung Y.S., Kim K.H., Kim K.R., Kwon G.H., Choi Y.H., H.K. Lee, "Social capital and oral health: The association of social capital with edentulism and chewing ability in the rural elderly," Archives of Gerontology and 
Geriatrics, vol. 74, pp. 100-105, 2018. DOI: 10.1016/j.archger.2017.10.002.

[17] Sun J., Xiao T., Lyu S., R. Zhao, "The Relationship between Social Capital and Depressive Symptoms Among the Elderly in China: The Mediating Role of Life Satisfaction," Risk Management and Healthcare Policy, vol. 18, no. 13, pp. 205-213, 2020. DOI: 10.2147/RMHP.S247355.

[18] Sundquist K., Hamano T., Li X., Kawakami N., Shiwaku K., J. Sundquist, "Linking social capital and mortality in the elderly: a Swedish national cohort study," Experimental Gerontology, vol. 55, pp. 29-36, 2014. DOI: 10.1016/j.exger.2014.03.007.

[19] Gontijo C.F., Firmo J., Lima-Costa M.F., A.I. de Loyola Filho, "A longitudinal study of the association between social capital and mortality in community-dwelling elderly Brazilians," Cadernos de Saude Publica, vol. 35, no. 2, p. e00056418, 2019. DOI: 10.1590/0102-311X00056418.

[20] Khongboon P., P. Sathirakorn, "Estimating Long-Term Care Costs among Thai Elderly: A Phichit Province Case Study," Journal of Aging Research, vol. 2018, no. 2, pp. 1-11, 2018. DOI: $10.1155 / 2018 / 4180565$

[21] B. Teerawichitchainan, "Older persons in Thailand: an update from a recent national survey," Asian Population Studies, vol. 16, no. 3, pp. 243-247, 2020. DOI: $10.1080 / 17441730.2020 .1794311$.

[22] A. Amornrat, "Financial and Social Capitals of Older adults in Thailand," Asian Social Science, vol. 8, no. 15, pp. 147156, 2012. DOI:10.5539/ASS.V8N15P147.

[23] Aung M.N., Moolphate S., Aung T.N., Katonyoo C., Khamchai S., P. Wannakrairot. "The social network index and its relation to later-life depression among the elderly aged $\geq 80$ years in Northern Thailand," Clinical Interventions in Aging, vol. 11, pp. 1067-1074, 2016. DOI: 10.2147/CIA.S108974.

[24] Punyakaew A., Lersilp S., S Putthinoi, "Active Ageing Level and Time Use of Elderly Persons in a Thai Suburban Community," Occupational Therapy International, vol. 2019, p. 7092695, 2019. DOI: 10.1155/2019/7092695.

[25] Somrongthong R., Wongchalee S., Ramakrishnan C., Hongthong D., Yodmai K., N. Wongtongkam, "Influence of Socioeconomic Factors on Daily Life Activities and Quality of Life of Thai Elderly," Journal of Public Health Research, vol. 6, no. 1, p. 862, 2017. DOI: 10.4081/jphr.2017.862.

[26] Sasiwongsaroj K., Wada T., Okumiya K., Imai H., Ishimoto Y., Sakamoto R., Fujisawa M., Kimura Y., Chen W.L., Fukutomi E., K. Matsubayashi, "Buddhist social networks and health in old age: A study in central Thailand," Geriatrics Gerontology International, vol. 15, no. 11, pp. 1210-1218, 2015. DOI: 10.1111/ggi.12421.

[27] Knodel J., Teerawichitchainan B., Prachuabmoh V., W. Pothisiri, "The situation of Thailand's older population: An update based on the 2014 Survey of Older Persons in Thailand," Singapore Management University, https://ink.library.smu.edu.sg/cgi/viewcontent.cgi?article= 3205\&context=soss_research (accessed Aug 12, 2021).

[28] De Silva M.J., Harpham T., Tuan T., Bartolini R., Penny M.E., S.R. Huttly, "Psychometric and cognitive validation of a social capital measurement tool in Peru and Vietnam,"
Social Science \& Medicine, vol. 62. no. 4, pp. 941-953, 2006. DOI: 10.1016/j.socscimed.2005.06.050.

[29] Sato Y., Pongvongsa T., Nonaka D., Kounnavong S., Nansounthavong P., Moji K., Phongmany P., Kamiya Y., Sato M., J. Kobayas, "Village health volunteers' social capital related to their performance in Lao People's Democratic Republic: a cross-sectional study," BMC Health Services Research, vol. 14, no. 1, p. 123, 2014. DOI: 10.1186/1472-6963-14-123.

[30] Takahashi K., Thuy N.T.M., Poudel K.C., Sakisaka K., Jimba M., J. Yasuoka, "Social capital and life satisfaction: a cross-sectional study on persons with musculoskeletal impairments in Hanoi, Vietnam, " BMC Public Health, vol. 11, p. 206, 2011. DOI: 10.1186/1471-2458-11-206.

[31] Onyx J., P. Bullen, "Measuring Social Capital in Five Communities," The Journal of Applied Behavioral Science, vol. 36, no. 1, pp. 23-42, 2011. DOI: $10.1177 / 0021886300361002$.

[32] Chariyalertsak S., Wansom T., Kawichai S., Ruangyuttikarna C., Kemerer V.F., A.W. Wu, "Reliability and validity of Thai versions of the MOS-HIV and SF-12 quality of life questionnaires in people living with HIV/AIDS," Health and Quality of Life Outcomes, vol. 9, no. 15, pp. 1-9, 2011, DOI: 10.1186/1477-7525-9-15.

[33] Diener E., Emmons R.A., Larsen R.J., S. Griffin, "The Satisfaction With Life Scale," Journal of Personality Assessment, vol. 49, no. 1, pp. 71-75, 1985. DOI: 10.1207/s15327752jpa4901_13.

[34] Kawachi I., Subramanian S. V., D. Kim, "Social Capital and Health," Springer, 2008, pp. 85-87.

[35] Yiengprugsawan V., Khamman S., Seubsman S.A., Lim L.L., A.C. Sleigh, "Social capital and health in a national cohort of 82,482 Open University adults in Thailand," Journal of Health Psychology, vol. 16, no. 4, pp. 632-642, 2011. DOI: $10.1177 / 1359105310386264$.

[36] G.A. Kaplan, "Social Determinants of Health," 2nd ed, Oxford University Press, 2006.

[37] Muckenhuber J., Pollak L., Stein K.V., T.E. Dorner, "Individual Cognitive Social Capital and Its Relationship with Pain and Sick Leave Due to Pain in the Austrian Population," PLoS One, vol. 11, no. 6, p. e0157909, 2016, DOI: 10.1371/journal.pone.0157909

[38] Cain C.L., Wallace S.P., N.A. Ponce, "Helpfulness, Trust, and Safety of Neighborhoods: Social Capital, Household Income, and Self-Reported Health of Older Adults," The Gerontologist, vol. 58, no. 1, pp. 4-14, 2018. DOI: $10.1093 /$ geront/gnx145.

[39] Gonyea J.G., Curley A., Melekis K., Y. Lee, "Perceptions of neighborhood safety and depressive symptoms among older minority urban subsidized housing residents: the mediating effect of sense of community belonging," Aging \& Mental Health, vol. 22, no. 12, pp. 1564-1569, 2018. DOI: $10.1080 / 13607863.2017 .1383970$.

[40] D. Takagi, "Neighborhood social Capital and Crime," in Global Perspectives on Social Capital and Health, Springer, 2013, pp. 145-147.

[41] Won J., Lee C., Forjuoh S.N., M.G. Ory, "Neighborhood 
safety factors associated with older adults' health-related outcomes: A systematic literature review," Social Science \& Medicine, vol. 165, pp. 177-186, 2016. DOI: 10.1016/j.socscimed.2016.07.024.

[42] Legatum Institute, "The Legatum Prosperity Index ${ }^{\mathrm{TM}}$ : A tool for transformation, $14^{\text {th }}$ ed, 2020.

[43] Amornsiriphonga S., S. Piemyat, "Social Capital: Means of Social Safety Net and Social Protection in Thai Communities," Procedia Engineering, vol. 32, pp. 11521156, 2012. DOI: 10.1016/j.proeng.2012.02.070. 